\title{
Using Benzodiazepines And Z-Drugs in The Management of Insomina, A Brief Review
}

\author{
Behzad Saberi* \\ Medical Research, Esfahan, Iran \\ *Corresponding author: Behzad Saberi, Medical Research, Esfahan, Iran
}

\begin{tabular}{|c|c|}
\hline ARTICLE INFO & ABSTRACT \\
\hline Received: 仹 October 28, 2020 & Citation: Behzad Saberi. Using Benzodiazepines And Z-Drugs in The Management of \\
\hline Published: 㹃 November 10, 2020 & Insomina, A Brief Review. Biomed J Sci \& Tech Res 31(5)-2020. BJSTR. MS.ID.005157. \\
\hline
\end{tabular}

\section{Introduction}

Insomnia as the most common disorder of sleep, can be classified as primary and secondary. In primary insomnia there are problems in the brain sleep mechanisms while in secondary insomnia, physical disorders, psychiatric diseases, drug use, and chronic pain can cause the problem. Promotion of sleep can become possible by using hypnotics. Chloral hydrate, barbiturates, chlormethiazole, benzodiazepines and Z-drugs are among hypnotic drugs. Benzodiazepines and Z-drugs are most commonly used as hypnotics. GABA-mediated inhibition enhancement in the CNS [1], would cause various actions of the benzodiazepines. GABA-A receptors in the CNS have modulatory sites which one of such modulatory sites is for benzodiazepines. When such modulatory site is activated, it causes GABA receptor's conformational change and it results in increasing in the GABA binding affinity and enhancing in the GABA actions on the conduction of the $\mathrm{Cl}$ in the membrane of the neurons [2]. Benzodiazepines can induce sleep. Some of them which possess a rapid elimination property like temazepam, are preferred clinically when avoiding daytime sedation would be a goal in the treatment.

Drowsiness, ataxia, alertness impairment and dependence are among the side effects of using benzodiazepines. Sudden stop in taking benzodiazepines, causes physical withdrawal syndrome to appear which shows itself with some symptoms like insomnia, anxiety, etc. Z-drugs are agonists for benzodiazepines receptor $[3,4]$. Their structure is different from the structure of the benzodiazepines. Their half-lives are shorter and daytime sedation with taking them is less likely to happen in comparison with benzodiazepines. Withdrawal and tolerance are also less likely to happen with Z-drugs in comparison with benzodiazepines. Zaleplon, zopiclone and zolpidem are some examples of these drugs. In the management of insomnia, Z-drugs are becoming more popular. Benzodiazepines and Z-drugs are two important categories of medications to use in the management of insomnia [5]. Healthcare professionals who are dealing with the patients with insomnia should have enough knowledge about these two important categories of medications which are used in the treatment of insomnia during clinical practice.

\section{References}

1. Brandt J, Leong C (2017) Benzodiazepines and Z-drugs: an updated review of major adverse outcomes reported on in epidemiologic research. Drugs R\&D 17(4): 493-507.

2. Riemann D, Baglioni C, Bassetti C, Bjorvatn B, Dolenc Groselj L, et al. (2017) European guideline for the diagnosis and treatment of insomnia. J Sleep Res 26(6): 675-700.

3. Schutte Rodin S, Broch L, Buysse D, Dorsey C, Sateia M, et al. (2008) Clinical guideline for the evaluation and management of chronic insomnia in adults. J Clin Sleep Med 4(5): 487-504.

4. Janhsen K, Roser P, Hoffmann K (2015) The problems of long-term treatment with benzodiazepines and related substances. Dtsch Arztebl Int 112(1-2): 1-7.

5. Sateia MJ, Buysse DJ, Krystal AD, Neubauer DN, Heald JL, et al. (2017) Clinical practice guideline for the pharmacologic treatment of chronic insomnia in adults: an American Academy of sleep medicine clinical practice guideline. J Clin Sleep Med 13(2): 307-349. 
ISSN: 2574-1241

DOI: 10.26717/BJSTR.2020.31.005157

Behzad Saberi. Biomed J Sci \& Tech Res

(c) (P) This work is licensed under Creative

Submission Link: https://biomedres.us/submit-manuscript.php

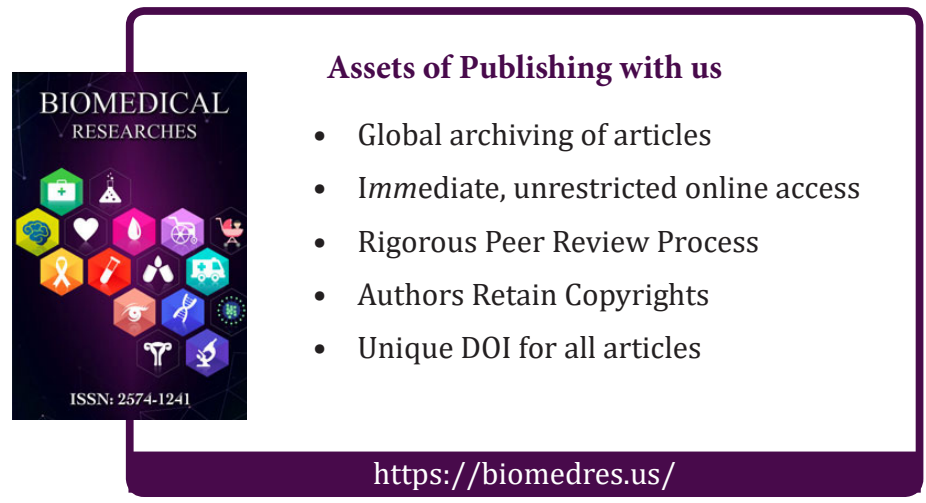

